\title{
National trends in cerebral bypass for unruptured intracranial aneurysms: a National (Nationwide) Inpatient Sample analysis of 1998-2015
}

\author{
Mayur Sharma, MD, MCh, Beatrice Ugiliweneza, PhD, MSPH, Enzo M. Fortuny, MD, \\ Nicolas K. Khattar, MD, Noberto Andaluz, MD, Robert F. James, MD, Brian J. Williams, MD, \\ Maxwell Boakye, MD, MPH, MBA, and Dale Ding, MD \\ Department of Neurosurgery, University of Louisville, Kentucky
}

OBJECTIVE The development and recent widespread dissemination of flow diverters may have reduced the utilization of surgical bypass procedures to treat complex or giant unruptured intracranial aneurysms (UIAs). The aim of this retrospective cohort study was to observe trends in cerebral revascularization procedures for UIAs in the United States before and after the introduction of flow diverters by using the National (Nationwide) Inpatient Sample (NIS).

METHODS The authors extracted data from the NIS database for the years 1998-2015 using the ICD-9/10 diagnostic and procedure codes. Patients with a primary diagnosis of UIA with a concurrent bypass procedure were included in the study. Outcomes and hospital charges were analyzed.

RESULTS A total of 216,212 patients had a primary diagnosis of UIA during the study period. The number of patients diagnosed with a UIA increased by $128 \%$ from $1998(n=7718)$ to $2015(n=17,600)$. Only 1328 of the UIA patients $(0.6 \%)$ underwent cerebral bypass. The percentage of patients who underwent bypass in the flow diverter era (2010-2015) remained stable at $0.4 \%$. Most patients who underwent bypass were white $(51 \%)$, were female $(62 \%)$, had a median household income in the 3rd or 4th quartiles (57\%), and had private insurance $(51 \%)$. The West $(33 \%)$ and Midwest/North Central regions (30\%) had the highest volume of bypasses, whereas the Northeast region had the lowest (15\%). Compared to the period 1998-2011, bypass procedures for UIAs in 2012-2015 shifted entirely to urban teaching hospitals (100\%) and to an elective basis (77\%). The median hospital stay (9 vs 3 days, $p<0.0001)$, median hospital charges $(\$ 186,746$ vs $\$ 66,361, p<0.0001)$, and rate of any complication (51\% vs $17 \%, p<0.0001)$ were approximately threefold higher for the UIA patients with bypass than for those without bypass.

CONCLUSIONS Despite a significant increase in the diagnosis of UIAs over the 17-year study period, the proportion of bypass procedures performed as part of their treatment has remained stable. Therefore, advances in endovascular aneurysm therapy do not appear to have affected the volume of bypass procedures performed in the UIA population. The authors' findings suggest a potentially ongoing niche for bypass procedures in the contemporary treatment of UIAs.

https://thejns.org/doi/abs/10.3171/2018.11.FOCUS18504

KEYWORDS national trends; cerebral revascularization; unruptured aneurysms; National (Nationwide) Inpatient Sample

$\mathrm{U}$ NRUPTURED intracranial aneurysms (UIAs) have traditionally been reported to have a prevalence of $1 \%-2 \%$, and they account for up to $85 \%$ of spontaneous subarachnoid hemorrhages. ${ }^{8}$ More recently, the increased use of neuroimaging modalities has led to an escalated frequency of UIA diagnoses, with prevalences of $7 \%$ in patients between 35 and 75 years of age $e^{20}$ and $8.8 \%$ overall. $^{19}$

The International Study of Unruptured Intracranial Aneurysms (ISUIA) ${ }^{46}$ reported 5-year cumulative hemorrhage risks, stratified by aneurysm size and location, that ranged from $0 \%$ for small anterior circulation UIAs to

ABBREVIATIONS FDA = Food and Drug Administration; ICD = International Classification of Diseases; NIS = National (Nationwide) Inpatient Sample; PED = Pipeline embolization device; UIA = unruptured intracranial aneurysm; US = United States.

SUBMITTED October 2, 2018. ACCEPTED November 8, 2018.

INCLUDE WHEN CITING DOI: 10.3171/2018.11.FOCUS18504. 
$50 \%$ for giant posterior circulation UIAs. A recent morphometric analysis of aneurysms in the ISUIA revealed that, in addition to the previously reported risk factors of aneurysm size and location, the perpendicular height of the aneurysm and its size ratio (i.e., ratio of maximum aneurysm diameter to parent vessel diameter) were also important predictors of UIA rupture risk. ${ }^{25}$ Given the high rupture risk associated with giant (diameter $>25 \mathrm{~mm}$ ) UIAs, treatment of these lesions should be considered.

Since the introduction of extracranial-intracranial bypass for the treatment of cerebral ischemia by Yasargil et al. ${ }^{47,48}$ in the 1970 s, the indications for revascularization have expanded to the treatment of complex and giant aneurysms, which became popularized in the 1980s. ${ }^{39,41,42}$ The International Subarachnoid Aneurysm Trial (ISAT) ${ }^{26,27}$ and Barrow Ruptured Aneurysm Trial (BRAT) ${ }^{24,37,38}$ reported better interim and long-term outcomes with endovascular therapy than with surgical clipping for ruptured aneurysms. However, no randomized trials have compared endovascular versus surgical treatment for UIAs, and most of the literature pertaining to UIAs is in the form of retrospective series and meta-analyses. . $^{3,10,14,31,34,36}$ Technological advances in endovascular therapy have led to an increase in endovascular procedures as the treatment of choice for cerebral aneurysms, from $20 \%$ of all aneurysms in 2001 to $63 \%$ in 2008.7 The introduction of flow-diverting stents has afforded neuroendovascular surgeons the opportunity to treat otherwise challenging aneurysms (e.g., giant, recurrent, fusiform, dissecting) by endoluminal reconstruction of the affected parent vessel, which results in progressive aneurysm occlusion over time while preserving flow through the parent artery., ${ }^{4,13,21,30}$ Since substantial overlap may exist between UIAs treated with surgical bypass and those treated with endovascular flow diversion, we hypothesized that the advent and subsequent dissemination of flow diverters, specifically the Pipeline embolization device (PED; Medtronic Neurovascular) which was approved by the United States (US) Food and Drug Administration (FDA) in April 2011, may be associated with a decline in the utilization of bypass for UIAs. Therefore, the aim of this retrospective cohort study was to evaluate temporal trends in cerebral revascularization procedures for UIAs in the US by using the National (Nationwide) Inpatient Sample (NIS), with particular consideration of the modern flow diversion era.

\section{Methods}

Data Source

We extracted data from the Healthcare Cost and Utilization Project (HCUP) NIS, which was established as a federal-state-industry partnership sponsored by the Agency for Healthcare Research and Quality (AHRQ) and is the largest all-payer inpatient care database. Data are released annually, dating back to 1988. Prior to 2012, the NIS data represented a $20 \%$ stratified sample of nonfederal community hospitals in the US. Beginning in 2012, the NIS approximates a 20\% sample of all discharges from community hospitals (excluding rehabilitation and long-term acute care hospitals) in the US. Weights are provided to obtain national estimates. Unweighted, the NIS comprises approximately 7 million hospital stays per year. Weighted, the NIS represents about 35 million hospital stays per year. The discharge abstract includes both the Clinical Classification Software (CCS) and International Classification of Diseases, 9th and 10th Revisions (ICD-9/10) diagnostic and procedure codes. ${ }^{12}$ The data contain information regarding admission and discharge status, demographic data, charges, length of stay, geographic locations, complications, and mortality. The NIS has been used to analyze national trends in healthcare use and charges, in quality and outcomes, and in policy. ${ }^{15,16,22,23,28,32,44}$ For this study, we used NIS data from 1998 to 2015.

\section{Case Selection}

Cases were hospitalizations in which patients had a primary diagnosis code of "cerebral aneurysm, nonruptured" (ICD-9 code 437.3 or ICD-10 code I671) with a concurrent procedure code of "bypass" (ICD-9 code 39.28 or ICD-10 codes $031 \mathrm{G}, 031 \mathrm{H}, 031 \mathrm{~J}, 031 \mathrm{~K}, 031 \mathrm{~L}, 031 \mathrm{M}, 031 \mathrm{~N}, 031 \mathrm{~S}$, 031T).

\section{Patient Characteristics}

The following patient characteristics were extracted: age, sex, race/ethnicity, comorbidity score, median household income by zip code, and primary payer. The comorbidity score was measured with the Elixhauser comorbidity index ${ }^{12}$ whose score was computed using an adaptation to ICD-9 and ICD-10 codes developed by Quan et al. ${ }^{29}$ The median household income by zip code was categorized in quartiles, from 1 (lowest) to 4 (highest).

\section{Hospital Characteristics}

The following hospital characteristics were extracted: hospital bed size (small, medium, or large), hospital region (Northeast, Midwest/North Central, South, or West), hospital location and/or teaching status (rural, urban nonteaching, or urban teaching), and admission/service type (emergent or elective).

\section{In-Hospital Outcomes}

The outcomes were length of stay, hospital charges, and complications. Hospital charges were adjusted to 2015 US\$ using the Medicare care component of the consumer price index (accessible through the Bureau of Labor Statistics). In our analysis, we included diagnosis codes for the following complications: renal, cardiac, neurological, neurosurgical, deep vein thrombosis and/or pulmonary embolism, infection, wound, hydrocephalus, mechanical ventilation, pneumonia, and laceration. The ICD-9 and ICD-10 codes were used to survey complications.

\section{Statistical Analysis}

Continuous variables were summarized as the mean with standard deviation or the median with interquartile range and full range, as appropriate. Categorical variables and outcomes were summarized as the frequency count and percentage. For statistical comparisons, we used gen- 
TABLE 1. Number of cases per year, 1998-2015

\begin{tabular}{|c|c|c|c|c|}
\hline \multirow[b]{2}{*}{ Year } & \multirow{2}{*}{$\begin{array}{l}\text { No. w/ Primary } \\
\text { Dx of UIA }\end{array}$} & \multicolumn{2}{|c|}{$\begin{array}{l}\text { Bypass as Primary or } \\
\text { Secondary Procedure }\end{array}$} & \multirow{2}{*}{$\begin{array}{c}\text { SE of } \\
\text { Percentage }\end{array}$} \\
\hline & & No. & $\%$ & \\
\hline 1998 & 7,718 & 23 & 0.30 & 0.14 \\
\hline 1999 & 9,248 & 165 & 1.78 & 0.63 \\
\hline 2000 & 9,091 & 85 & 0.93 & 0.22 \\
\hline 2001 & 8,388 & 47 & 0.56 & 0.24 \\
\hline 2002 & 8,099 & 66 & 0.81 & 0.4 \\
\hline 2003 & 11,690 & 97 & 0.83 & 0.22 \\
\hline 2004 & 10,861 & 37 & 0.34 & 0.15 \\
\hline 2005 & 10,537 & 73 & 0.69 & 0.22 \\
\hline 2006 & 14,318 & 106 & 0.74 & 0.22 \\
\hline 2007 & 11,758 & 66 & 0.56 & 0.21 \\
\hline 2008 & 15,128 & 66 & 0.44 & 0.12 \\
\hline 2009 & 13,995 & 143 & 1.02 & 0.33 \\
\hline 2010 & 1,112 & 5 & 0.45 & 0.44 \\
\hline 2011 & 17,059 & 64 & 0.38 & 0.16 \\
\hline 2012 & 16,785 & 75 & 0.45 & 0.12 \\
\hline 2013 & 16,620 & 50 & 0.30 & 0.09 \\
\hline 2014 & 16,205 & 75 & 0.46 & 0.13 \\
\hline 2015 & 17,600 & 85 & 0.48 & 0.11 \\
\hline
\end{tabular}

$\mathrm{Dx}=$ diagnosis; $\mathrm{SE}=$ standard error .

eralized linear models adjusted for the clustered and stratified nature of the data. To determine whether there was a specific year during which the trend significantly changed, we used Joinpoint Regression. The significance level was set to a $\mathrm{p}$ value $<0.05$, and all statistical tests were twosided. Data analyses were performed using SAS (SAS Institute) and Joinpoint Regression Software (Joinpoint Regression Program, version 4.6.0.0, April 2018, Statisti- cal Methodology and Applications Branch, Surveillance Research Program, National Cancer Institute).

\section{Results}

The study cohort comprised 216,212 patients with a primary diagnosis of UIA during the study period. Table 1 details the number of primary diagnosis codes for UIA and the number of primary or secondary procedure codes for bypass for each year of the study period (1998-2015). The number of patients with UIA as the primary diagnosis increased by $128 \%$ from $1998(n=7718)$ to $2015(n=$ $17,600)$. However, the yearly proportion of UIA patients undergoing cerebral bypass remained stable during the study period (Fig. 1), ranging from $0.3 \%$ (1998) to $1.8 \%$ (1999). In the more recent flow diverter era (2010-2015), the annual percentage of UIA patients undergoing bypass remained stable at approximately $0.4 \%$ (Fig. 2).

\section{Patient Demographics and Cerebral Bypass}

A total of 1328 UIA patients ( $0.6 \%$ of the study cohort) underwent cerebral bypass. Table 2 summarizes the demographics of the study cohort, compares the demographics of UIA patients with versus without bypass, and compares the demographics of UIA patients who underwent bypass in 1998-2011 versus 2012-2015. The UIA patients who underwent bypass were younger (median age 56 vs 57 years, $\mathrm{p}<0.0001$ ), and if the UIA patient was male, they were more likely to undergo bypass $(38 \%$ vs $26 \%$, p $<0.0001$ ). The majority of patients who underwent bypass for UIA were white (51\%), had an Elixhauser comorbidity index $\geq 3(51 \%)$, had a median household income in the 3rd or 4th quartile (57\%), and were privately insured (51\%). Significant differences between UIA patients who underwent bypass and those who did not were observed for race/ethnicity $(\mathrm{p}<0.0001)$, comorbidity index $(\mathrm{p}=$ $0.0035)$, median household income $(\mathrm{p}<0.0001)$, and insurance $(p<0.0001)$. We also found significant differ-

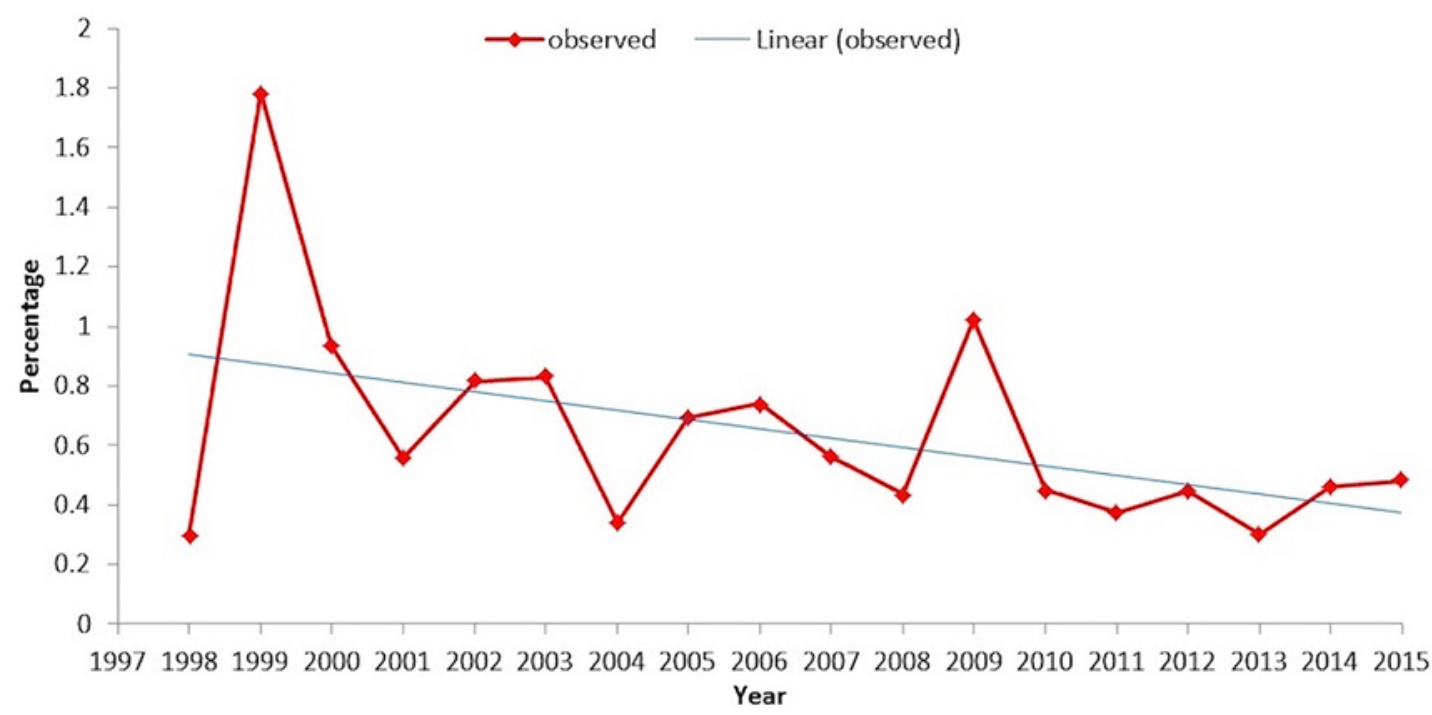

FIG. 1. Rate of primary bypasses performed for primary UIAs per year, 1998-2015. 


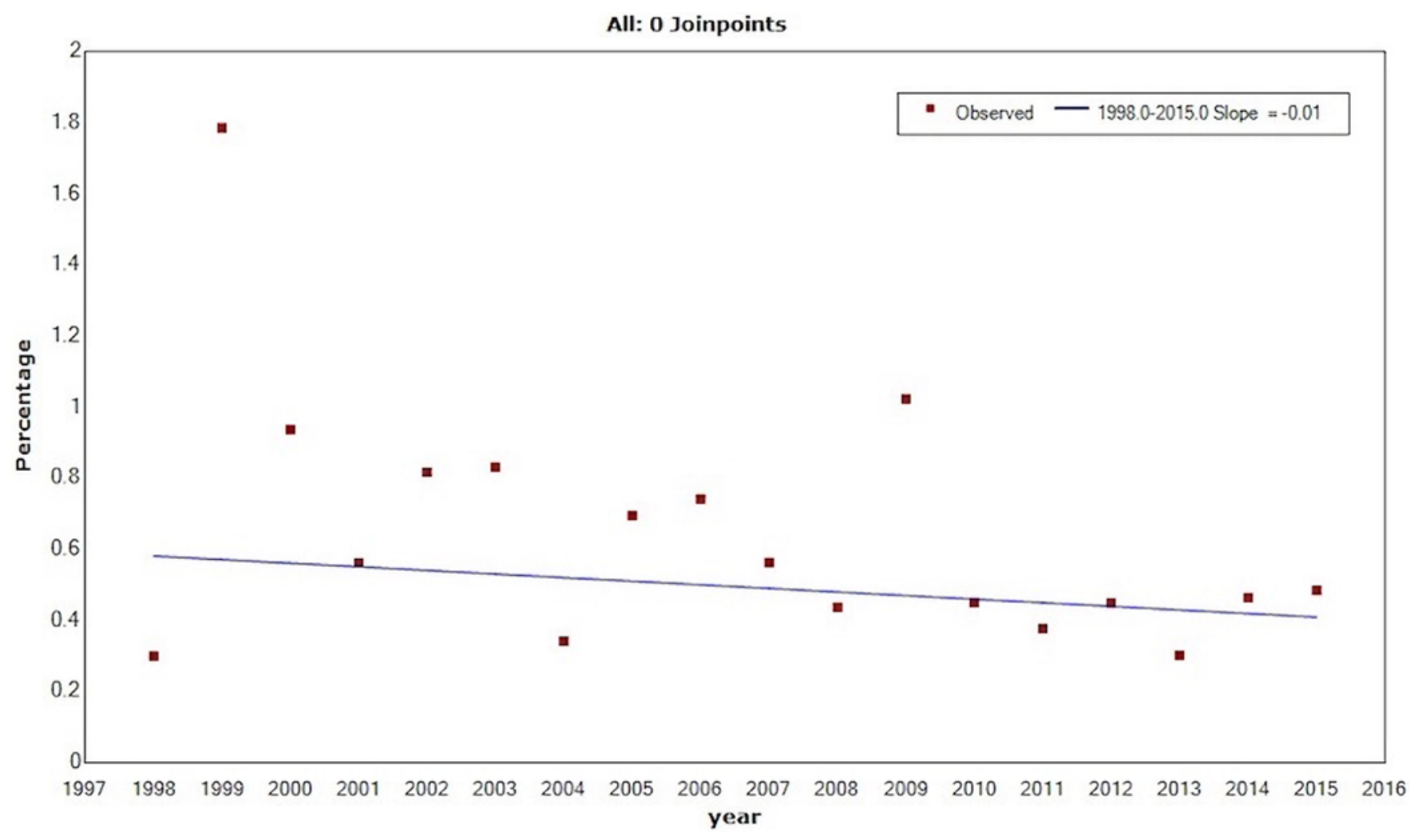

FIG. 2. Results from Joinpoint Regression Software. Red boxes indicate observed percentage of UIA patients undergoing bypass; blue line indicates $1998-2015$ slope $=-0.01$. Slope is significantly different from 0 at alpha $=0.05$ level. Final selected model: 0 Joinpoints.

ences in race/ethnicity $(\mathrm{p}<0.0001)$, comorbidity index $(\mathrm{p}=0.0071)$, median household income $(\mathrm{p}<0.0001)$, and insurance $(\mathrm{p}<0.0001)$ between patients who underwent bypass in 1998-2011 and those who did so in 2012-2015.

\section{Hospital Characteristics and Cerebral Bypass}

Table 3 summarizes the hospital characteristics of the study cohort, compares the hospital characteristics of UIA patients with versus without bypass, and compares the hospital characteristics of UIA patients who underwent bypass in 1998-2011 versus 2012-2015. When considering geographic distribution, the majority of bypass procedures were performed in the West (33\%) and Midwest/ North Central region hospitals $(30 \%)$, with Northeast region hospitals performing the least (15\%). In this 17-year patient sample, most bypass procedures for UIAs were performed at large (83\%) and urban teaching $(96 \%)$ hospitals and on an elective basis (67\%). Compared to the time period of 1998-2011, bypass procedures for UIAs in the years 2012-2015 shifted entirely to urban teaching hospitals $(100 \%)$ and were more frequently performed on an elective basis $(77 \%)$.

Significant differences were observed in hospital bed size $(\mathrm{p}<0.0001)$, hospital region $(\mathrm{p}<0.0001)$, hospital location and teaching status $(\mathrm{p}<0.0001)$, and admission/ service type $(\mathrm{p}<0.0001)$ between UIA patients who underwent bypass and those who did not. We also found significant differences in hospital bed size $(\mathrm{p}=0.0089)$, hospital region $(\mathrm{p}=0.0003)$, hospital location and teaching status $(\mathrm{p}=0.0003)$, and admission/service type $(\mathrm{p}<$ 0.0001 ) between patients who underwent bypass for UIA in 1998-2011 and those who did so in 2012-2015.

\section{Length of Stay, Hospital Costs, and Complications Following Bypass for UIA}

Table 4 summarizes the length of stay, hospital costs, and postoperative complications of the study cohort, compares these factors between UIA patients with and those without bypass, and compares these factors between UIA patients who underwent bypass in 1998-2011 and those who did so in 2012-2015. The median hospital stay (9 vs 3 days, $\mathrm{p}<0.0001)$ and median hospital charges $(\$ 186,746$ vs $\$ 66,361, p<0.0001)$ were three times greater for the UIA patients who underwent bypass than for those who did not. The rate of any complication was also three times higher in the UIA patients who underwent bypass $(51 \%$ vs $17 \%, \mathrm{p}<0.0001$ ).

Compared to the years 1998-2011, the median length of stay following bypass for UIA remained unchanged in 2012-2015 (9 vs 8 days, respectively, $p=0.1660$ ). However, the median cost of hospitalization for bypass in UIA patients increased from $\$ 174,311$ in 1998-2011 to $\$ 232,460$ in 2012-2015 ( $\mathrm{p}<0.0001$ ). Although the rate of any postoperative complication after bypass for UIA was not significantly different in 1998-2011 compared with 20122015 (50\% vs 53\%, respectively, $\mathrm{p}=0.4547$ ), the rates of 
TABLE 2. Demographics of patients diagnosed with UIA

\begin{tabular}{|c|c|c|c|c|c|c|c|}
\hline \multirow[b]{2}{*}{ Variable } & \multicolumn{4}{|c|}{$\begin{array}{c}\text { Patients w/ Primary Dx } \\
\text { of UIA }\end{array}$} & \multicolumn{3}{|c|}{$\begin{array}{c}\text { Patients w/ Bypass Surgery } \\
\text { for UIA }\end{array}$} \\
\hline & All & No CB & $\mathrm{CB}$ & p Value & 1998-2011 & 2012-2015 & $p$ Value \\
\hline No. of patients & 216,212 & 214,884 & 1,328 & & 1,043 & 285 & \\
\hline \multicolumn{8}{|l|}{ Age in yrs } \\
\hline Mean (SD) & $57(30)$ & $57(30)$ & $52(37)$ & & $52(36)$ & $50(42)$ & \\
\hline Median (Q1-Q3) & $57(48-66)$ & $57(48-66)$ & $56(42-63)$ & $<0.0001$ & $56(44-64)$ & $55(38-63)$ & 0.5146 \\
\hline Range, min-max & $0-100$ & $0-100$ & $0-85$ & & $10-84$ & $0-85$ & \\
\hline \multicolumn{8}{|l|}{ Sex, no. (\%) } \\
\hline Male & $56,204(26 \%)$ & $55,699(26 \%)$ & $505(38 \%)$ & & $410(39 \%)$ & $95(33 \%)$ & \\
\hline Female & $159,337(74 \%)$ & $158,514(74 \%)$ & $823(62 \%)$ & $<0.0001$ & $633(61 \%)$ & $190(67 \%)$ & 0.0646 \\
\hline Data missing & $671(0 \%)$ & $671(0 \%)$ & $0(0 \%)$ & & $0(0 \%)$ & $0(0 \%)$ & \\
\hline \multicolumn{8}{|l|}{ Race/ethnicity, no. (\%) } \\
\hline White & $124,790(58 \%)$ & $124,118(58 \%)$ & $672(51 \%)$ & & $502(48 \%)$ & $170(60 \%)$ & \\
\hline Black & $20,575(10 \%)$ & $20,502(10 \%)$ & $73(5 \%)$ & $<0.0001$ & $48(5 \%)$ & $25(9 \%)$ & $<0.0001$ \\
\hline Other & $27,171(13 \%)$ & $26,986(13 \%)$ & $184(14 \%)$ & & $124(12 \%)$ & $60(21 \%)$ & \\
\hline Data missing & $43,677(20 \%)$ & $43,278(20 \%)$ & $399(30 \%)$ & & $369(35 \%)$ & $30(11 \%)$ & \\
\hline \multicolumn{8}{|l|}{ Elixhauser index, no. (\%) } \\
\hline 0 & $679(0 \%)$ & $679(0 \%)$ & $0(0 \%)$ & & $0(0 \%)$ & $0(0 \%)$ & \\
\hline 1 & $49,483(23 \%)$ & $49,201(23 \%)$ & $282(21 \%)$ & 0.0035 & $232(22 \%)$ & $50(18 \%)$ & 0.0071 \\
\hline 2 & $64,262(30 \%)$ & $63,899(30 \%)$ & $363(27 \%)$ & & $298(29 \%)$ & $65(23 \%)$ & \\
\hline 3 or more & $101,788(47 \%)$ & $101,105(47 \%)$ & $683(51 \%)$ & & $513(49 \%)$ & $170(60 \%)$ & \\
\hline \multicolumn{8}{|c|}{ Median household income for patient's zip code, no. (\%) } \\
\hline Quartile 1 & $45,407(21 \%)$ & $45,195(21 \%)$ & $213(16 \%)$ & & $138(13 \%)$ & $75(26 \%)$ & \\
\hline Quartile 2 & $54,204(25 \%)$ & $53,912(25 \%)$ & $292(22 \%)$ & & $207(20 \%)$ & $85(30 \%)$ & \\
\hline Quartile 3 & $55,109(25 \%)$ & $54,796(26 \%)$ & $313(24 \%)$ & $<0.0001$ & $258(25 \%)$ & $55(19 \%)$ & $<0.0001$ \\
\hline Quartile 4 & $56,360(26 \%)$ & $55,922(26 \%)$ & $438(33 \%)$ & & $393(38 \%)$ & $45(16 \%)$ & \\
\hline Data missing & $5,133(26 \%)$ & $5,059(2 \%)$ & $72(5 \%)$ & & $47(5 \%)$ & $25(9 \%)$ & \\
\hline \multicolumn{8}{|l|}{ Primary payer, no. (\%) } \\
\hline Medicare & $71,478(33 \%)$ & $71,110(33 \%)$ & $368(28 \%)$ & & $298(29 \%)$ & $70(25 \%)$ & \\
\hline Medicaid & $24,168(11 \%)$ & $23,984(11 \%)$ & $184(14 \%)$ & & $114(11 \%)$ & $70(25 \%)$ & \\
\hline Private & $103,102(48 \%)$ & $102,428(48 \%)$ & $673(51 \%)$ & & $548(53 \%)$ & $125(44 \%)$ & \\
\hline Self-pay & $8,009(4 \%)$ & $7,976(4 \%)$ & $33(3 \%)$ & $<0.0001$ & $28(3 \%)$ & $5(2 \%)$ & $<0.0001$ \\
\hline No charge & $1,180(1 \%)$ & $1,180(1 \%)$ & $0(0 \%)$ & & $0(0 \%)$ & $0(0 \%)$ & \\
\hline Other & $7,829(1 \%)$ & $7,759(4 \%)$ & $70(5 \%)$ & & $55(5 \%)$ & $15(5 \%)$ & \\
\hline Data missing & $447(0 \%)$ & $447(0 \%)$ & $0(0 \%)$ & & $0(0 \%)$ & $0(0 \%)$ & \\
\hline
\end{tabular}

$\mathrm{CB}=$ cerebral bypass; $\mathrm{SD}=$ standard deviation .

Boldface type indicates statistical significance.

renal $(1 \%$ vs $0 \%, \mathrm{p}=0.0447)$, neurosurgical $(26 \%$ vs $18 \%$, $\mathrm{p}=0.0028)$, wound $(2 \%$ vs $0 \%, \mathrm{p}=0.0347)$, mechanical ventilation $(16 \%$ vs $11 \%, \mathrm{p}=0.0175)$, and laceration ( $3 \%$ vs $0 \%, \mathrm{p}=0.0045)$ complications decreased from 1998-2011 to 2012-2015, whereas the rates of neurological (2\% vs $16 \%, \mathrm{p}<0.0001)$ and infectious (8\% vs $16 \%, \mathrm{p}=0.0002)$ complications increased from 1998-2011 to 2012-2015.

\section{Discussion}

In this retrospective cohort study, whose data were derived from an analysis of the NIS for the period from 1998 to 2015, we found that cerebral bypass continues to be performed in a very small proportion of UIA patients in the US. Despite the introduction of endovascular flow diversion for the treatment of UIA, ${ }^{5}$ the annual rates of bypass procedures performed for UIAs remained stable at a low rate (mean $0.4 \%$ ), even in the context of an increased frequency of UIA diagnosis by $128 \%$ during the study period.

Our findings reject the supposition that the application and dissemination of flow diverters for UIAs have reduced the utilization of bypass as a treatment method. As shown by our results, the percentage of patients undergoing cerebral bypass for UIAs has remained largely unchanged between 1998 and 2015, with no change in trends since 
TABLE 3. Hospital characteristics for study cohort

\begin{tabular}{|c|c|c|c|c|c|c|c|}
\hline \multirow[b]{2}{*}{ Variable } & \multicolumn{4}{|c|}{ Patients w/ Primary Dx of UIA } & \multicolumn{3}{|c|}{ Patients w/ CB for UIA } \\
\hline & All & No CB & CB & $p$ Value & 1998-2011 & 2012-2015 & $p$ Value \\
\hline No. of patients & 216,212 & 214,884 & 1,328 & & 1,043 & 285 & \\
\hline \multicolumn{8}{|l|}{ Hospital bed size, no. (\%) } \\
\hline Small & $12,255(6 \%)$ & $12,153(6 \%)$ & $102(8 \%)$ & & $92(9 \%)$ & $10(4 \%)$ & \\
\hline Medium & $33,868(16 \%)$ & $33,743(16 \%)$ & $125(9 \%)$ & $<0.0001$ & $100(10 \%)$ & $25(9 \%)$ & 0.0089 \\
\hline Large & $169,314(78 \%)$ & $168,213(78 \%)$ & $1,101(83 \%)$ & & $851(82 \%)$ & $250(88 \%)$ & \\
\hline Data missing & $775(0 \%)$ & $775(0 \%)$ & $0(0 \%)$ & & $0(0 \%)$ & $0(0 \%)$ & \\
\hline \multicolumn{8}{|l|}{ Hospital region, no. (\%) } \\
\hline Northeast & $41,605(19 \%)$ & $41,400(19 \%)$ & $205(15 \%)$ & & $150(14 \%)$ & $55(19 \%)$ & \\
\hline Midwest/North Central & $53,521(25 \%)$ & $53,125(25 \%)$ & $396(30 \%)$ & $<0.0001$ & $291(28 \%)$ & $105(37 \%)$ & 0.0003 \\
\hline South & $77,206(36 \%)$ & $76,923(36 \%)$ & $283(21 \%)$ & & $228(22 \%)$ & $55(19 \%)$ & \\
\hline West & $43,880(20 \%)$ & $43,436(20 \%)$ & $444(33 \%)$ & & $374(36 \%)$ & $70(25 \%)$ & \\
\hline \multicolumn{8}{|l|}{$\begin{array}{l}\text { Hospital location/teaching } \\
\text { status, no. (\%) }\end{array}$} \\
\hline Rural & $3,723(2 \%)$ & $3,708(2 \%)$ & $15(1 \%)$ & & $15(1 \%)$ & $0(0 \%)$ & \\
\hline Urban non-teaching & $28,466(13 \%)$ & $28,424(13 \%)$ & $42(3 \%)$ & $<0.0001$ & $42(4 \%)$ & $0(0 \%)$ & 0.0003 \\
\hline Urban teaching & $183,247(85 \%)$ & $181,976(85 \%)$ & $1,271(96 \%)$ & & $986(95 \%)$ & $285(100 \%)$ & \\
\hline Data missing & $776(0 \%)$ & $776(0 \%)$ & $0(0 \%)$ & & $0(0 \%)$ & $0(0 \%)$ & \\
\hline \multicolumn{8}{|c|}{ Admission/service type, no. (\%) } \\
\hline Emergency & $27,699(13 \%)$ & $27,590(13 \%)$ & $109(8 \%)$ & & $109(10 \%)$ & $0(0 \%)$ & \\
\hline Elective & $140,724(65 \%)$ & $139,838(65 \%)$ & $886(67 \%)$ & $<0.0001$ & $666(64 \%)$ & $220(77 \%)$ & $<0.0001$ \\
\hline Missing & $47,789(22 \%)$ & $47,456(22 \%)$ & $333(25 \%)$ & & $268(26 \%)$ & $65(23 \%)$ & \\
\hline
\end{tabular}

Boldface type indicates statistical significance.

FDA approval of the PED in 2011. Bypass is still overwhelmingly performed by large academic hospitals, which may be due to the procedure's technical complexity and the relatively few neurosurgeons who have retained expertise in the procedure. ${ }^{17}$ Our study showed that bypass procedures for the treatment of UIAs have shifted entirely to urban teaching hospitals in the time period 2012-2015. This may reflect a consolidation of referral patterns toward high-volume academic centers of excellence. .,2,17,33,39 $^{2}$

Our analysis has shown that the bypass is predominantly performed in individuals with an Elixhauser comorbidity index of 2 or greater (77\%) and is virtually never performed in individuals with a score of 0 . This suggests that certain comorbidities may play a role in the progression of aneurysms to the complex lesions requiring bypass. Unsurprisingly, bypass correlated with significantly longer hospital stays and admission costs. This could be related to a more intensive use of resources or the inherent complexity of UIAs not amenable to more conventional treatments such as endovascular therapy or surgical clipping.

A noticeable finding was the much higher complication rates in patients undergoing bypass than in those who did not $(51 \%$ vs $17 \%, \mathrm{p}<0.0001)$. This difference could be partly explained by the previously noted difference in the prevalence of comorbidities between the two groups, making patients in the bypass group more vulnerable to complications arising from preexisting medical problems. This difference could also be attributed to an increased operative morbidity associated with bypass procedures and the technical complexities arising from the lesions themselves. ${ }^{17}$ It should also be noted that the overall complication rate in patients undergoing bypass has gradually decreased over time. This could be explained by improvements in surgical techniques, the patient concentration in high-volume academic centers, and changes in the selection criteria for bypass in light of emerging endovascular options. ${ }^{40}$

Our results challenge the notion that the emergence of flow diversion has decreased the need for cerebral bypass in the contemporary management of UIAs not amenable to endovascular coiling or surgical clipping, which implies that many of those complex lesions that warrant bypass surgery are still not amenable to flow diversion or other novel endovascular devices. Despite its high costs and need for prolonged hospitalization, cerebral bypass remains necessary for certain aneurysms with challenging anatomy or giant aneurysms, both of which are poor candidates for flow diversion. ${ }^{35}$ Bypass appears to provide a high cure rate with good vessel patency in appropriately selected patients ${ }^{18}$ and continues to represent an acceptable alternative for aneurysms that are otherwise untreatable by other means. Therefore, training future generations of vascular neurosurgeons in developing and maintaining proficiency in this surgical technique is paramount in keeping this modality available for these complicated aneurysms.

We can hypothesize, based on FDA approval of the PED for proximal internal carotid artery aneurysms from the petrous to superior hypophyseal segments, that more 


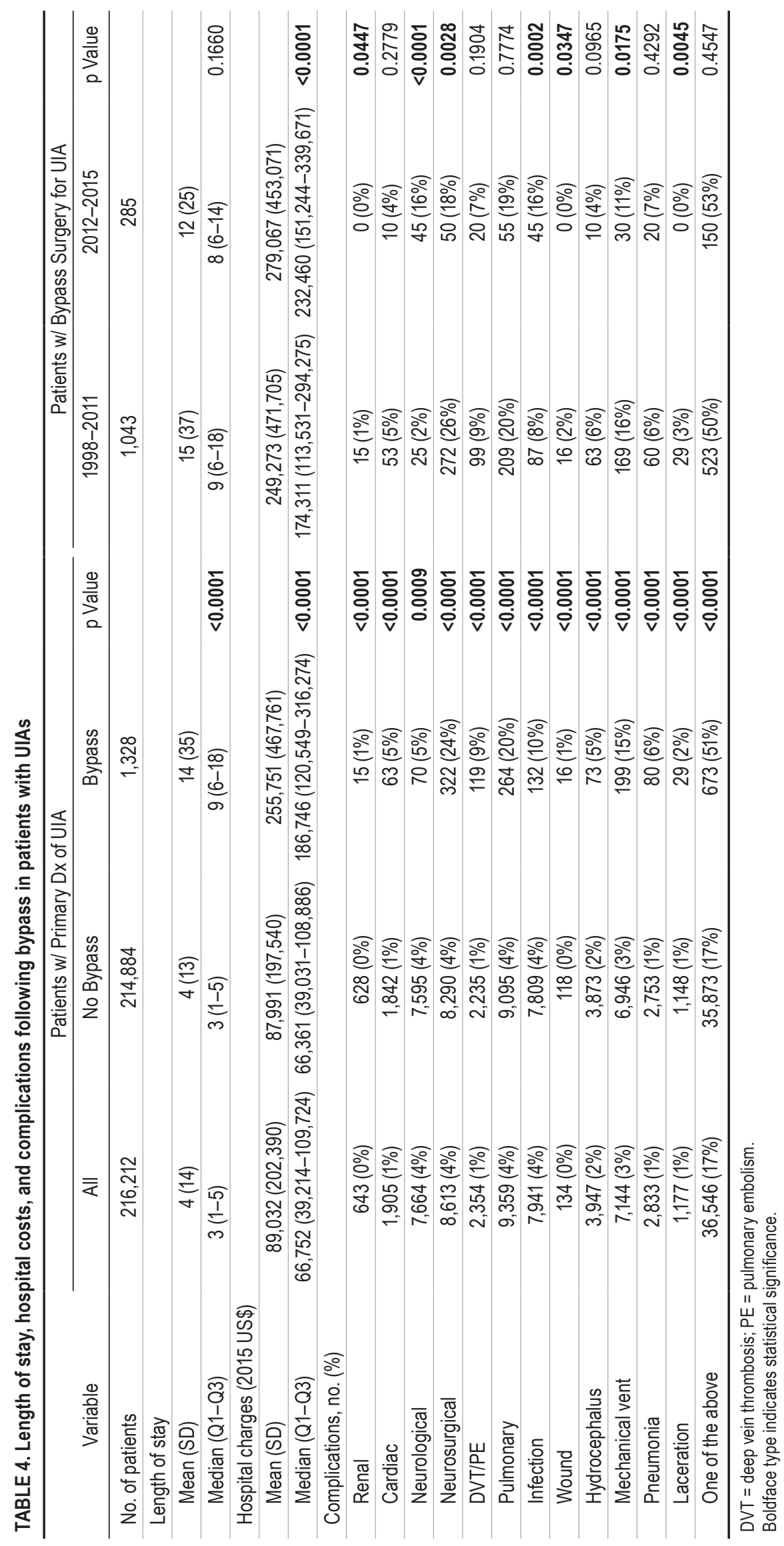


recent bypasses may be used more frequently for distally located aneurysms (e.g., anterior cerebral artery, middle cerebral artery, posterior inferior cerebellar artery) for which flow diversion has not yet been proven or accepted as the preferred treatment. ${ }^{5,50}$ Based on the available literature, there does not appear to be a substantial change in the rates of graft vessel patency over time (i.e., pre- 45 vs post-PED ${ }^{43,49}$ eras), although recent publications from the US have suggested an increasing preference for the radial artery as the interposition graft of choice rather than the saphenous vein. ${ }^{6,9,11,33}$ However, we emphasize that these trends are inferred from the literature and cannot be informed by the NIS database used in this study.

\section{Study Strengths and Limitations}

The NIS provides a large sample size and an opportunity to look at the trends and practice patterns across the US. Researchers who query this database can answer a question in a comprehensive manner. The NIS also provides inpatient outcomes and hospitalization charges.

Limitations associated with the NIS include those associated with a retrospective cohort study (e.g., selection, treatment, and referral biases), coding errors, underestimation of mortality, and an inability to provide detailed long-term clinical outcomes. The NIS does not provide longitudinal information such as inpatient and outpatient services, medications, and overall costs related to outcome. Thus, we were unable to ascertain from the NIS any changes in treatment paradigm, graft choice, graft patency, or long-term clinical outcomes over the study period. We were also unable to determine the specific type or severity of postoperative neurological or neurosurgical complications. Additionally, the clinical indication for bypass, type and location of aneurysms, neuroimaging data, and clinical decision-making involved in the selection of UIA patients for bypass cannot be extracted from this database. Another major limitation of our study is the lack of data from the NIS with respect to the use of flow diversion because endovascular aneurysm embolization procedure codes do not currently distinguish between coiling and flow diversion. Therefore, it is possible that the complexity of UIAs undergoing intervention has increased over time, concurrently with the increased frequency of UIA diagnoses, thereby potentially expanding the indications of bypass for the treatment of aneurysms that cannot be adequately occluded with flow diverters.

\section{Conclusions}

Cerebral revascularization appears to have maintained a role in the treatment of UIAs over the past two decades, despite concurrent advances in endovascular techniques and devices in this time period. The impact of the introduction and subsequent propagation of endovascular flow diversion techniques on the rates of bypass procedures performed for the treatment of UIAs appears to be limited. Further detailed studies are warranted to evaluate the riskbenefit profiles of various revascularization approaches for the treatment of UIAs not amenable to surgical clipping or endovascular therapy. While challenging in the contemporary era of aneurysm treatment, the development and maintenance of expertise in cerebral bypass techniques at high-volume centers of excellence remain necessary for the comprehensive management of particularly difficult cases.

\section{References}

1. Abla AA, Lawton MT: Anterior cerebral artery bypass for complex aneurysms: an experience with intracranial-intracranial reconstruction and review of bypass options. J Neurosurg 120:1364-1377, 2014

2. Abla AA, McDougall CM, Breshears JD, Lawton MT: Intracranial-to-intracranial bypass for posterior inferior cerebellar artery aneurysms: options, technical challenges, and results in 35 patients. J Neurosurg 124:1275-1286, 2016

3. Alshekhlee A, Mehta S, Edgell RC, Vora N, Feen E, Mohammadi A, et al: Hospital mortality and complications of electively clipped or coiled unruptured intracranial aneurysm. Stroke 41:1471-1476, 2010

4. Becske T, Brinjikji W, Potts MB, Kallmes DF, Shapiro M, Moran CJ, et al: Long-term clinical and angiographic outcomes following Pipeline embolization device treatment of complex internal carotid artery aneurysms: five-year results of the Pipeline for Uncoilable or Failed Aneurysms trial. Neurosurgery 80:40-48, 2017

5. Becske T, Kallmes DF, Saatci I, McDougall CG, Szikora I, Lanzino G, et al: Pipeline for Uncoilable or Failed Aneurysms: results from a multicenter clinical trial. Radiology 267:858-868, 2013

6. Benet A, Tabani H, Bang JS, Meybodi AT, Lawton MT: Occipital artery to anterior inferior cerebellar artery bypass with radial artery interposition graft for vertebrobasilar insufficiency: 3-dimensional operative video. Oper Neurosurg (Hagerstown) 13:641, 2017

7. Brinjikji W, Rabinstein AA, Nasr DM, Lanzino G, Kallmes DF, Cloft HJ: Better outcomes with treatment by coiling relative to clipping of unruptured intracranial aneurysms in the United States, 2001-2008. AJNR Am J Neuroradiol 32:1071-1075, 2011

8. Brown RD Jr, Broderick JP: Unruptured intracranial aneurysms: epidemiology, natural history, management options, and familial screening. Lancet Neurol 13:393-404, 2014

9. Burkhardt JK, Winkler E, Tabani H, Gandhi S, Benet A, Lawton MT: A2 anterior cerebral artery-to-A3 anterior cerebral artery interpositional bypass with radial artery graft for a ruptured mycotic fusiform aneurysm: 2-dimensional operative video. Oper Neurosurg (Hagerstown) 15:601, 2018

10. Cowan JA Jr, Ziewacz J, Dimick JB, Upchurch GR Jr, Thompson BG: Use of endovascular coil embolization and surgical clip occlusion for cerebral artery aneurysms. J Neurosurg 107:530-535, 2007

11. Czabanka M, Ali M, Schmiedek P, Vajkoczy P, Lawton MT: Vertebral artery-posterior inferior cerebellar artery bypass using a radial artery graft for hemorrhagic dissecting vertebral artery aneurysms: surgical technique and report of 2 cases. J Neurosurg 114:1074-1079, 2011

12. Elixhauser A, Steiner C, Harris DR, Coffey RM: Comorbidity measures for use with administrative data. Med Care 36:8-27, 1998

13. Fiorella D, Lylyk P, Szikora I, Kelly ME, Albuquerque FC, McDougall CG, et al: Curative cerebrovascular reconstruction with the Pipeline embolization device: the emergence of definitive endovascular therapy for intracranial aneurysms. J Neurointerv Surg 10 (Suppl 1):i9-i18, 2018

14. Hwang JS, Hyun MK, Lee HJ, Choi JE, Kim JH, Lee NR, et al: Endovascular coiling versus neurosurgical clipping in patients with unruptured intracranial aneurysm: a systematic review. BMC Neurol 12:99, 2012 
15. Kalakoti P, Missios S, Maiti T, Konar S, Bir S, Bollam P, et al: Inpatient outcomes and postoperative complications after primary versus revision lumbar spinal fusion surgeries for degenerative lumbar disc disease: a National (Nationwide) Inpatient Sample Analysis, 2002-2011. World Neurosurg 85:114-124, 2016

16. Kourtis AP, Bansil P, Posner SF, Johnson C, Jamieson DJ: Trends in hospitalizations of HIV-infected children and adolescents in the United States: analysis of data from the 19942003 Nationwide Inpatient Sample. Pediatrics 120:e236e243, 2007

17. Lawton MT, Abla AA, Rutledge WC, Benet A, Zador Z, Rayz VL, et al: Bypass surgery for the treatment of dolichoectatic basilar trunk aneurysms: a work in progress. Neurosurgery 79:83-99, 2016

18. Lee CH, Tsai ST, Chiu TL: Superficial temporal arterymiddle cerebral artery bypass for the treatment of complex middle cerebral artery aneurysms. Ci Ji Yi Xue Za Zhi 30:110-115, 2018

19. Li J, Shen B, Ma C, Liu L, Ren L, Fang Y, et al: 3D contrast enhancement-MR angiography for imaging of unruptured cerebral aneurysms: a hospital-based prevalence study. PLoS One 9:e114157, 2014

20. Li MH, Chen SW, Li YD, Chen YC, Cheng YS, Hu DJ, et al: Prevalence of unruptured cerebral aneurysms in Chinese adults aged 35 to 75 years: a cross-sectional study. Ann Intern Med 159:514-521, 2013

21. Lylyk P, Miranda C, Ceratto R, Ferrario A, Scrivano E, Luna $\mathrm{HR}$, et al: Curative endovascular reconstruction of cerebral aneurysms with the Pipeline embolization device: the Buenos Aires experience. Neurosurgery 64:632-643, 2009

22. Makarov DV, Loeb S, Landman AB, Nielsen ME, Gross CP, Leslie DL, et al: Regional variation in total cost per radical prostatectomy in the healthcare cost and utilization project Nationwide Inpatient Sample database. J Urol 183:15041509,2010

23. McCutcheon BA, Chang DC, Marcus L, Gonda DD, Noorbakhsh A, Chen CC, et al: Treatment biases in traumatic neurosurgical care: a retrospective study of the Nationwide Inpatient Sample from 1998 to 2009. J Neurosurg 123:406-414, 2015

24. McDougall CG, Spetzler RF, Zabramski JM, Partovi S, Hills NK, Nakaji P, et al: The Barrow Ruptured Aneurysm Trial. J Neurosurg 116:135-144, 2012

25. Mocco J, Brown RD Jr, Torner JC, Capuano AW, Fargen KM, Raghavan ML, et al: Aneurysm morphology and prediction of rupture: an International Study of Unruptured Intracranial Aneurysms analysis. Neurosurgery 82:491-496, 2018

26. Molyneux A, Kerr R, Stratton I, Sandercock P, Clarke M, Shrimpton J, et al: International Subarachnoid Aneurysm Trial (ISAT) of neurosurgical clipping versus endovascular coiling in 2143 patients with ruptured intracranial aneurysms: a randomised trial. Lancet 360:1267-1274, 2002

27. Molyneux AJ, Kerr RS, Yu LM, Clarke M, Sneade M, Yarnold JA, et al: International Subarachnoid Aneurysm Trial (ISAT) of neurosurgical clipping versus endovascular coiling in 2143 patients with ruptured intracranial aneurysms: a randomised comparison of effects on survival, dependency, seizures, rebleeding, subgroups, and aneurysm occlusion. Lancet 366:809-817, 2005

28. Opila T, George A, El-Ghanem M, Souayah N: Trends in outcomes and hospitalization charges of infant botulism in the United States: a comparative analysis between Kids' Inpatient Database and National Inpatient Sample. Pediatr Neurol 67:53-58, 2017

29. Quan H, Sundararajan V, Halfon P, Fong A, Burnand B, Luthi JC, et al: Coding algorithms for defining comorbidities in ICD-9-CM and ICD-10 administrative data. Med Care 43:1130-1139, 2005
30. Raper DM, Ding D, Peterson EC, Crowley RW, Liu KC, Chalouhi N, et al: Cavernous carotid aneurysms: a new treatment paradigm in the era of flow diversion. Expert Rev Neurother 17:155-163, 2017

31. Ruan C, Long H, Sun H, He M, Yang K, Zhang H, et al: Endovascular coiling vs. surgical clipping for unruptured intracranial aneurysm: a meta-analysis. Br J Neurosurg 29:485-492, 2015

32. Schraufnagel D, Rajaee S, Millham FH: How many sunsets? Timing of surgery in adhesive small bowel obstruction: a study of the Nationwide Inpatient Sample. J Trauma Acute Care Surg 74:181-189, 2013

33. Sekhar LN, Duff JM, Kalavakonda C, Olding M: Cerebral revascularization using radial artery grafts for the treatment of complex intracranial aneurysms: techniques and outcomes for 17 patients. Neurosurgery 49:646-659, 2001

34. Sharma M, Brown B, Madhugiri V, Cuellar-Saenz H, Sonig A, Ambekar S, et al: Unruptured intracranial aneurysms: comparison of perioperative complications, discharge disposition, outcome, and effect of calcification, between clipping and coiling: a single institution experience. Neurol India 61:270-276, 2013

35. Siddiqui AH, Abla AA, Kan P, Dumont TM, Jahshan S, Britz $\mathrm{GW}$, et al: Panacea or problem: flow diverters in the treatment of symptomatic large or giant fusiform vertebrobasilar aneurysms. J Neurosurg 116:1258-1266, 2012

36. Smith TR, Cote DJ, Dasenbrock HH, Hamade YJ, Zammar SG, El Tecle NE, et al: Comparison of the efficacy and safety of endovascular coiling versus microsurgical clipping for unruptured middle cerebral artery aneurysms: a systematic review and meta-analysis. World Neurosurg 84:942-953, 2015

37. Spetzler RF, McDougall CG, Albuquerque FC, Zabramski JM, Hills NK, Partovi S, et al: The Barrow Ruptured Aneurysm Trial: 3-year results. J Neurosurg 119:146-157, 2013

38. Spetzler RF, McDougall CG, Zabramski JM, Albuquerque FC, Hills NK, Russin JJ, et al: The Barrow Ruptured Aneurysm Trial: 6-year results. J Neurosurg 123:609-617, 2015

39. Spetzler RF, Schuster H, Roski RA: Elective extracranialintracranial arterial bypass in the treatment of inoperable giant aneurysms of the internal carotid artery. J Neurosurg 53:22-27, 1980

40. Starke RM, Turk A, Ding D, Crowley RW, Liu KC, Chalouhi $\mathrm{N}$, et al: Technology developments in endovascular treatment of intracranial aneurysms. J Neurointerv Surg 8:135-144, 2016

41. Sundt TM Jr, Piepgras DG, Houser OW, Campbell JK: Interposition saphenous vein grafts for advanced occlusive disease and large aneurysms in the posterior circulation. J Neurosurg 56:205-215, 1982

42. Sundt TM Jr, Piepgras DG, Marsh WR, Fode NC: Saphenous vein bypass grafts for giant aneurysms and intracranial occlusive disease. J Neurosurg 65:439-450, 1986

43. Tayebi Meybodi A, Huang W, Benet A, Kola O, Lawton MT: Bypass surgery for complex middle cerebral artery aneurysms: an algorithmic approach to revascularization. J Neurosurg 127:463-479, 2017

44. Tripathi B, Arora S, Kumar V, Abdelrahman M, Lahewala S, Dave M, et al: Temporal trends of in-hospital complications associated with catheter ablation of atrial fibrillation in the United States: an update from Nationwide Inpatient Sample database (2011-2014). J Cardiovasc Electrophysiol 29:715724,2018

45. Vishteh AG, Marciano FF, David CA, Schievink WI, Zabramski JM, Spetzler RF: Long-term graft patency rates and clinical outcomes after revascularization for symptomatic traumatic internal carotid artery dissection. Neurosurgery 43:761-768, 1998

46. Wiebers DO, Whisnant JP, Huston J III, Meissner I, Brown 
RD Jr, Piepgras DG, et al: Unruptured intracranial aneurysms: natural history, clinical outcome, and risks of surgical and endovascular treatment. Lancet 362:103-110, 2003

47. Yasargil MG, Krayenbuhl HA, Jacobson JH II: Microneurosurgical arterial reconstruction. Surgery 67:221-233, 1970

48. Yasargil MG, Yonekawa Y: Results of microsurgical extraintracranial arterial bypass in the treatment of cerebral ischemia. Neurosurgery 1:22-24, 1977

49. Yoon S, Burkhardt JK, Lawton MT: Long-term patency in cerebral revascularization surgery: an analysis of a consecutive series of 430 bypasses. J Neurosurg [epub ahead of print August 24, 2018. DOI: 10.3171/2018.3.JNS172158]

50. Zammar SG, Buell TJ, Chen CJ, Crowley RW, Ding D, Griessenauer CJ, et al: Outcomes after off-label use of the Pipeline embolization device for intracranial aneurysms: a multicenter cohort study. World Neurosurg 115:e200-e205, 2018

\section{Author Contributions}

Acquisition of data: Sharma. Analysis and interpretation of data: Sharma. Drafting the article: Sharma, Fortuny. Critically revising the article: Ding, Sharma, Ugiliweneza, Khattar, Andaluz, James, Williams. Reviewed submitted version of manuscript: Ding, Sharma, Ugiliweneza, Fortuny, Khattar, Andaluz, James, Williams. Statistical analysis: Ugiliweneza. Administrative/technical/material support: Ding, Boakye. Study supervision: Ding, Boakye.

\section{Correspondence}

Dale Ding: University of Louisville School of Medicine, Louisville, KY. daleding1234@gmail.com.

\section{Disclosures}

Dr. Williams has served as a consultant for Monteris. 